\title{
Effect of dealloying parameters on HER electrocatalytic performance of nanoporous silver
}

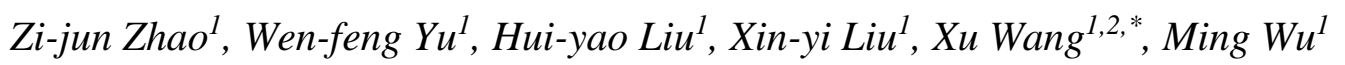 \\ ${ }^{1}$ School of Mechanical Engineering, Liaoning Petrochemical University, Fushun 113001, Liaoning, \\ China \\ ${ }^{2}$ Department of Materials Science \& Engineering; Hong Kong Institute for Advanced Study, City \\ University of Hong Kong, Kowloon, Hong Kong \\ *E-mail: wx1979875@hotmail.com
}

Received: 6 September 2021 / Accepted: 11 October 2021 / Published: 10 November 2021

\begin{abstract}
$\mathrm{Ag}_{15} \mathrm{Cu}_{85}$ binary alloy ribbon, as the precursor, was executed high-temperature oxidation at $650{ }^{\circ} \mathrm{C}$ and dealloying with different durations to fabricate nanoporous silver at different stages. The HER electrocatalytic performance of nanoporous silver at different stage was tested using open circuit potential (OCP), linear sweep voltammetry (LSV), and potential polarization curve. The results show that the nonporous silver electrode in the $\mathrm{B} 1$ stage has the best anti-toxic performance, Ecorr is $-0.088 \mathrm{~V}$, and the icorr is $1.2 \times 10^{-7} \mathrm{~A} / \mathrm{cm}^{2}$; the nanoporous silver electrode in the A2 stage shows the lowest Tafel

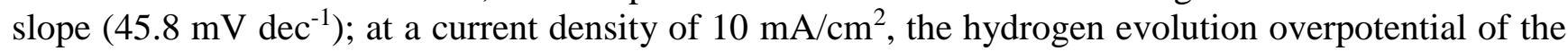
nanoporous silver electrode in the $\mathrm{B} 3$ stage is $37.6 \mathrm{mV}$. From all those electrochemical tests, the nanoporous silver electrode in the B1 stage exhibited the best comprehensive HER performance.
\end{abstract}

Keywords: nanoporous silver; hydrogen evolution performance; high-temperature oxidation; dealloying

\section{FULL TEXT}

(C) 2021 The Authors. Published by ESG (www.electrochemsci.org). This article is an open access article distributed under the terms and conditions of the Creative Commons Attribution license (http://creativecommons.org/licenses/by/4.0/). 